\title{
CLIMATOLOGIA E VARIABILIDADE SAZONAL DO NÚMERO DE ONDAS DE CALOR E DE FRIO NO RIO GRANDE DO SUL ASSOCIADAS AO ENOS
}

\author{
MÁRI ÂNDREA FELDMAN FIRPO ${ }^{1}$, CLÓVIS ANGELI SANSIGOLO ${ }^{1}$, SIMONE VIEIRA DE ASSIS ${ }^{2}$ \\ ${ }^{1}$ Instituto Nacional de Pesquisas Espaciais (INPE), São José dos Campos, SP, Brasil \\ ${ }^{2}$ Universidade Federal de Pelotas (UFPel), Pelotas, RS, Brasil
}

mari.firpo@cptec.inpe.br, clovis.sansigolo@cptec.inpe.br, assis@ufpel.tche.br

Recebido Agosto de 2010 - Aceito Agosto de 2011

\begin{abstract}
RESUMO
Este trabalho investiga a variabilidade sazonal das ocorrências de ondas de frio e calor no Rio Grande do Sul e suas relações com os eventos El Niño e La Niña. Foram utilizados dados de 13 estações de superfície bem distribuídas pelo Estado, no período de 39 anos, compreendido entre 1967 e 2005 . As relações entre ondas e ENOS foram obtidas a partir da análise de tabelas de contingência 2 × 2 para os meses centrais de cada estação do ano. A significância estatística foi avaliada através do teste exato de Fischer. Observou-se que a variabilidade sazonal das ondas de frio é diferente da variabilidade das ondas de calor. Ocorrem mais ondas de frio nos meses com as temperaturas mínimas mais baixas, e as ondas de calor têm comportamento mais heterogêneo. Na maioria das localidades, é em julho que as relações entre a ocorrência de ondas de calor e os eventos El Niño são mais significativas. Para La Niña e ondas de Frio, o mês com relações mais significativas foi abril. Em ambos os casos, nota-se que há defasagem entre a ocorrência dos eventos El Niño/La Niña e o seu impacto no surgimento de ondas de calor/frio.
\end{abstract}

Palavras-chave: ondas de frio, ondas de calor, ENOS, tabelas de contingência.

\begin{abstract}
CLIMATOLOGY AND SEASONAL VARIABILITY OF THE NUMBER OF WARM AND COLD WAVES IN RIO GRANDE DO SUL ASSOCIATED TO ENOS

This work investigates the seasonal variability occurrence of cold and warm waves in the Brazilian State of Rio Grande do Sul and its relationships with El Niño and La Niña events. 39 years (19672005) temperature data series from 13 uniformly distributed meteorological stations over the State were used. The relationships between waves and ENOS were obtained from $2 \times 2$ contingence table analysis for the central months of each season. The statistical significance was evaluated using the Fisher exact test. It was observed that the seasonal variability of cold waves is different than the warm wave variability. There are more cold waves during the months with lowest minimum temperatures, and the warm waves have a more heterogeneous behavior. In most localities, the relationships between the occurrence of the warm waves and El Niño events are more significant in July. For La Niña and cold waves, the month with more significant relationships is April. In both cases, there are lags between the El Niño/La Niña occurrence and their impact in the setting of warm/cold waves.
\end{abstract}

Keywords: cold waves, warm waves, ENSO, contingency tables.

\section{INTRODUÇÃO}

A Região Sul do Brasil, destacadamente o Rio Grande do Sul, por seu afastamento do Equador, sente os efeitos típicos de inverno característicos das regiões de clima temperado, durante os meses de junho a agosto. Isso ocorre devido a sucessivas e intensas incursões de massas de ar polares, acentuando a redução da temperatura que comumente atinge valores pouco superiores a $0^{\circ} \mathrm{C}$ e, às vezes, negativos. No verão, por outro lado, os dias são mais longos e a inclinação dos raios solares é pequena, o que contribui para que o forte calor se estabeleça. $\mathrm{O}$ verão climático desta região normalmente dura três meses, restrito a dezembro, janeiro e fevereiro, sendo janeiro o mais representativo da estação do ano.

É comum, durante os meses frios de inverno, a temperatura mínima ficar abaixo da normal climatológica, 
persistindo por dias seguidos, caracterizando uma onda de frio. Já durante o verão, ondas de calor também se estabelecem, e a temperatura máxima diária do ar pode ultrapassar a normal obtida para o período em análise. Ainda há que considerar as anomalias, tanto da temperatura máxima, quanto da temperatura mínima, abaixo e acima do valor normal climatológico esperado para qualquer estação do ano e para a localidade em estudo.

Rusticucci e Vargas (2001) definem "ondas" como seqüências diárias de anomalias de temperaturas com mesmo sinal. Assim, três parâmetros, neste evento, são considerados: o comprimento ou persistência (número de dias ininterruptos da anomalia, tendo o mesmo sinal), o valor máximo (anomalia positiva) ou mínimo (anomalia negativa) da onda e a "intensidade" (média de anomalias da onda).

O estudo climatológico das ondas de calor e de frio pode revelar uma associação com os sistemas determinantes da circulação geral da atmosfera, auxiliando no melhor entendimento do clima da região sul, especialmente do Rio Grande do Sul, estado em que a economia é baseada fortemente na agricultura e na pecuária, que dependem de condições climáticas favoráveis para o seu desenvolvimento.

Além dos fatores geográficos, como latitude, altitude, maritimidade e continentalidade, que exercem grande influência nas temperaturas do Estado, há também que ser considerado o impacto das variações nos padrões atmosféricos. Uma das escalas de variabilidade mais importantes, neste contexto, é a interanual. A maior parte da variabilidade interanual da atmosfera está claramente relacionada aos oceanos tropicais, e o mais importante modo de variabilidade interanual do sistema oceano-atmosfera é o El Niño/Oscilação Sul (ENOS) (Kilards e Mo, 1998; Kayano e Andreoli, 2007). Os efeitos do fenômeno ENOS são observados em escala global e alteram o regime térmico em diversas regiões do mundo (Ropelewski e Halpert, 1987; Kilards e Diaz, 1989). A Região Sul do Brasil pertence à chamada Região Sudeste da América do Sul (juntamente com o nordeste da Argentina, Uruguai e Sul do Paraguai), que apresenta forte sinal do ENOS (Ropelewski e Halpet, 1987; Studizinki e Diaz, 1994).

A relação entre os eventos El Niño e La Niña e os extremos de frio e calor no Cone Sul da América do Sul são discutidos por Grimm e Togatlian (2002). Estes concluíram que o aumento da freqüência de eventos severos frios, durante La Niña, é maior do que a diminuição de eventos severos quentes; assim como o aumento da freqüência de eventos severos quentes, durante El Niño, é maior que a diminuição de eventos severos frios; ou seja, estes eventos contribuem para aumentar a variabilidade da temperatura diária.

Segundo Bidegain e Renom (2002), o ENOS influencia claramente as localidades uruguaias mais quentes e continentais. Além disso, constataram que na fase fria (La Niña) as temperaturas mínimas são menores que as normais e as máximas são maiores do que o esperado, ou seja, há uma maior amplitude térmica, enquanto na fase quente (El Niño) a amplitude térmica diária é menor.

Outros autores também documentaram a relação entre a Oscilação Sul e as anomalias climáticas sobre a América do Sul. Rusticucci e Vargas (2001) analisam o possível efeito do El Niño na ocorrência das ondas extremas sobre a Argentina. Eles apontam que as ondas de calor, no inverno, são mais persistentes no ano de El Niño e mais intensas no inverno seguinte. Já nos meses mais quentes, estas ondas se apresentam mais intensas quando ocorre La Niña. Quanto às ondas de frio que alcançam o norte do país, estas são mais persistentes em meses de La Niña, com o risco das massas de ar frio alcançarem latitudes menores nesta fase do ENOS.

Quanto aos mecanismos que explicam essas relações, Arkin (1982) sugeriu que anomalias de TSM, associadas ao ENOS, induzem a intensificação da corrente de jato em ambos os hemisférios, tendo influência nos padrões mensais e sazonais de precipitação e temperatura, em várias regiões do globo. Isso ocorre, porque na fase quente do ENOS, a circulação de Walker é enfraquecida; assim a célula de Hadley anômala no Pacífico leste configura-se contrária à do Pacífico oeste (Wang, 2002). Esses resultados concordam com o encontrado anteriormente por Bjerknes (1966), em seu trabalho pioneiro, onde descreveu, na fase quente do ENOS, um aumento da circulação de Hadley, conduzida por forte convecção sobre o Pacífico Central; circulação esta que, através da transferência de fluxo meridional de momentum, pode manter um forte jato subtropical. Rao e Hada (1990) sugeriram que na fase negativa da Oscilação Sul, o fortalecimento da circulação de Hadley mantém o jato subtropical mais forte. Esta situação do escoamento em altitude mantém os sistemas frontais no sul do Brasil. Segundo Grimm (2003), episódios de El Niño onde o gradiente latitudinal de TSM foi fraco não produziram impacto significativo no sudeste da América do Sul. Isso porque esse gradiente fortalece o jato subtropical e favorece a propagação das ondas de Rossby do Pacífico Tropical leste em direção a essa Região.

Dentro deste contexto, o objetivo desse trabalho foi descrever a variabilidade sazonal da ocorrência de ondas de frio e calor, no Rio Grande do Sul, associadas ao ENOS.

\section{DADOS E METODOLOGIA}

\subsection{Dados}

Para a realização deste estudo foram analisados dados de 13 estações meteorológicas de superfície, que representam regiões distintas do Estado do Rio Grande do Sul, e pertencem à rede de estações do $8^{\circ}$ Distrito de Meteorologia do Instituto 
Nacional de Meteorologia (INMET) e da Fundação Estadual de Pesquisa Agropecuária (FEPAGRO). A série temporal é composta por dados diários de temperaturas máximas e mínimas absolutas do ar, medida em graus Celsius $\left({ }^{\circ} \mathrm{C}\right)$, no período de 1967 a 2005. A Figura 1 mostra a distribuição destas estações sobre o relevo do RS.

\subsection{Comportamento das temperaturas máximas e mínimas}

$\mathrm{Na}$ primeira parte deste trabalho, foi calculada a climatologia dos extremos de temperaturas máximas e mínimas do ar, a fim de observar o comportamento das mesmas, antes de realizar-se o estudo das ondas de frio e calor. A análise foi feita a partir dos valores do limite superior ao quarto quartil das temperaturas máximas e do limite inferior ao primeiro quartil das temperaturas mínimas, para os 4 meses centrais referentes às 4 estações do ano (janeiro, abril, julho e outubro), para as 13 estações meteorológicas presentes no estudo.

\subsection{Cálculo das ondas de frio e calor}

Para se obter as normais climatológicas diárias das temperaturas máxima e mínima absolutas do ar, nas estações meteorológicas, foi feita uma média aritmética, para cada dia do ano, nos 39 anos de dados (1967 - 2005). A partir da normal climatológica diária da série de dados foram obtidas, para cada ano, as ondas de calor e de frio. Isso se deu através do cálculo das anomalias, tanto de temperatura máxima, como de temperatura mínima. As anomalias são calculadas subtraindo a série climatológica das séries anuais (isto é, o valor observado menos

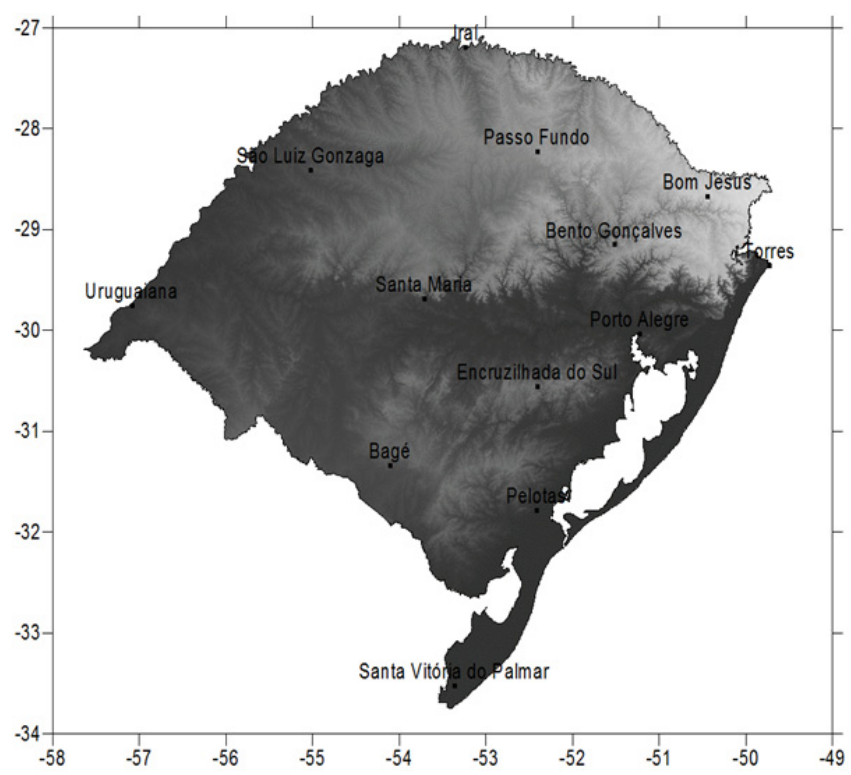

Figura 1 - Estações meteorológicas utilizadas no estudo o valor médio). Levaram-se em consideração as anomalias, tanto da temperatura máxima, quanto da temperatura mínima, com valores acima e abaixo, respectivamente, do valor normal climatológico esperado para cada dia do ano em questão e para a localidade em estudo. Foi designado "onda" o período de dias consecutivos de anomalias, tanto negativas como positivas, maior ou igual a cinco dias. Esse valor foi sugerido pelo fato dos sistemas transientes, que atuam e causam impactos muitas vezes severos na região, persistirem por, no mínimo, cerca de cinco dias (Cavalcanti e Kousky, 2009). Padronizou-se que ondas, as quais iniciam e finalizam em meses diferentes fossem truncadas. Isso se justifica pelo fato de que a análise das ondas será feita mensalmente. Obteve-se a freqüência dessas ondas e os meses de maior ocorrência.

Das treze estações selecionadas para o estudo, notou-se que em três destas (Passo Fundo, Pelotas e Porto Alegre) existiam sucessivas falhas de poucos dias, apesar do longo período de dados disponíveis. Tal fato não compromete integralmente o estudo climatológico das regiões, mas sim o cálculo das ondas, visto que para isso se faz necessária a contagem dos dias consecutivos de anomalias. Assim, optou-se por considerar as treze estações para a análise climatológica, mas somente as dez que apresentavam menos falhas para a contagem das ondas.

\subsection{Influência dos eventos EI Niño/ La Niña nas ondas de frio e de calor}

Verificou-se a influência dos fenômenos El Niño e La Niña nas ondas de frio e de calor e na ocorrência de geadas, com base nos meses de ocorrência de El Niño e La Niña, de acordo com a Tabela 1.

A partir dessas informações, foram organizadas tabelas de contingência para os meses centrais de cada estação do ano, a fim de considerar a influência das fases inicial (outubro), madura (janeiro) e dissipativa (abril) dos eventos. O período de inverno (julho) também foi considerado, pois além de ser a época do ano em que a amplitude térmica do Estado é maior, os impactos das temperaturas mínimas são mais alarmantes devido ao maior número de passagens de frentes (Cavalcanti e Kousky, 2003).

Assim, foram arranjadas tabelas de contingência $2 \times 2$, como mostrado na Tabela 2. Nessa tabela, $\mathbf{n}$ é o total de anos, das quais em a anos se observou a ocorrência de onda de calor (frio), sendo $\mathbf{x}$ durante evento El Niño (La Niña) (r) e a-x em anos Neutros ou de La Niña (El Niño), que totalizam n-r.

A significância do número de vezes que ocorreram ondas de calor (frio), numa determinada época em que estava presente o evento El Niño (La Niña), foi calculada de forma semelhante ao que foi feito por Sansigolo et al. (2006) ao buscarem relações 
Tabela 1 - Ocorrência dos eventos El Niño e La Niña entre 1967 e 2005.

\begin{tabular}{ccc|ccc}
\hline \multicolumn{2}{c|}{ EVENTOS DE EL NIÑO } & \multicolumn{3}{c}{ EVENTOS DE LA NIÑA } \\
\hline COMEÇO DO & FIM DO & TEMPO DE & COMEÇO DO & FIM DO & TEMPO DE \\
EVENTO & EVENTO & DURAÇÃO & EVENTO & EVENTO & DURAÇÃO \\
\hline SET 1968 & MAR 1970 & 19 & JUL 1970 & JAN 1972 & 19 \\
ABR 1972 & MAR 1973 & 12 & JUN 1973 & JUN 1974 & 13 \\
AGO 1976 & MAR 1977 & 8 & SET 1974 & ABR 1976 & 20 \\
JUL 1977 & JAN 1978 & 7 & SET 1984 & JUN 1985 & 10 \\
OUT 1979 & ABR 1980 & 16 & MAI 1988 & JUN 1989 & 14 \\
ABR 1982 & JUL 1983 & 16 & SET 1995 & MAR 1996 & 7 \\
AGO 1986 & FEV 1988 & 19 & *JUL 1998 & JUN 2000 & 24 \\
MAR 1991 & JUL 1992 & 17 & *JUL 2000 & FEV 2001 & 8 \\
FEV 1993 & SET 1993 & 8 & & & \\
JUN 1994 & MAR 1995 & 10 & & & \\
*ABR 1997 & JUN 1998 & 15 & & & \\
*ABR 2002 & MAR 2003 & 12 & & & \\
*JUN 2004 & ABR 2005 & 11 & & & \\
\hline
\end{tabular}

* Eventos acrescentados de acordo com os critérios de Trenberth (1997). Fonte: Trenberth, 1997.

Tabela 2 - Tabela de Contingência 2 × 2.

\begin{tabular}{c|c|c|c}
\hline \multirow{2}{*}{$\begin{array}{c}\text { Ondas de } \\
\text { Calor/Frio }\end{array}$} & \multicolumn{2}{|c|}{ El Niño/La Niña } & \\
\cline { 2 - 4 } Sim & Sim & Não & Total \\
\hline Não & $\mathrm{x}$ & $\mathrm{a}-\mathrm{x}$ & $\mathrm{a}$ \\
\hline Total & $\mathrm{r}-\mathrm{x}$ & $\mathrm{n}-\mathrm{r}-\mathrm{a}+\mathrm{x}$ & $\mathrm{n}-\mathrm{a}$ \\
\hline
\end{tabular}

entre o ENOS e as temperaturas médias sazonais no Rio Grande do Sul.

Foi utilizado o teste de significância exato de Fischer, indicado para tratar variáveis categóricas quando o tamanho das amostras independentes é pequeno, além de considerar todas as combinações possíveis que resultam nas mesmas freqüências marginais (Kendall e Stuart, 1979). O método está baseado na distribuição hipergeométrica, calculando a probabilidade de observar um determinado conjunto de freqüências na tabela, quando se consideram fixos os totais marginais, sob a hipótese de nulidade, ou seja, independência de variáveis.

A probabilidade de $\mathbf{x}$ ou mais anos com ondas de calor (frio), em uma amostra aleatória de a anos com ondas ocorrerem em $\mathbf{r}$ anos de El Niño (La Niña), é equivalente à área do limite superior da distribuição hipergeométrica (Agresti, 1996):

$$
P(X \geq x)=H(x \mid a, r, n)=\sum_{k=x}^{\min (a, r)} C_{r}^{k} C_{n-r}^{a-k} / C_{n}^{a}
$$

\section{RESULTADOS E DISCUSSÕES}

\subsection{Climatologia dos extremos de temperaturas máximas e mínimas}

As Figuras 2 e 3 indicam a distribuição espacial dos extremos de temperatura no Rio Grande do Sul, representando a probabilidade de $25 \%$ das temperaturas máximas (mínimas) estarem acima (abaixo) do valor limite descrito nas isolinhas para o $4^{\circ}$ quartil (o $1^{\circ}$ quartil).

Na Figura 2 observa-se que a distribuição espacial da temperatura máxima extrema apresenta valores crescentes à medida que se afasta do extremo sul e litoral em direção ao noroeste do estado, com a presença de um núcleo frio permanente na região de Bom Jesus (Serra do Sudeste). Esse forte efeito do relevo na temperatura do Estado também foi observado por Nímer (1989).

Na Figura 2a, referente ao mês de janeiro, observa-se uma zona quente a norte-noroeste. Gradualmente, a temperatura vai diminuindo ao longo do Estado, em direção ao litoral sul. Porém, observa-se uma zona fria em torno da estação de Bom Jesus (Serra Gaúcha) e, ainda, uma zona um pouco mais quente em torno de Porto Alegre. No mês de abril (Figura 2b) a Zona Quente de Porto Alegre (ZQP) permanece mais fraca, enquanto a Zona Quente do Norte (ZQN) direciona-se mais ao norte do Estado. Em julho (Figura 2c), há enfraquecimento, ainda, da Zona Fria em torno de Bom Jesus (ZFB) e surgimento de uma zona mais fria no sul do Estado (ZFS). No mês de outubro (Figura 2d) a ZQN continua posicionada mais ao norte. As ZFB e ZFS passam a coexistir.

$\mathrm{Na}$ Figura 3, tem-se a distribuição espacial das temperaturas mínimas para as localidades estudadas, para os meses centrais das 4 estações do ano, relativas ao limite inferior ao $1^{\circ}$ quartil. Elas representam a probabilidade de $25 \%$ de que se tenha, durante o período estudado, anos com temperaturas mínimas menores ou iguais ao valor limite, destacando os valores extremos mais baixos. Nessas figuras observa-se que, diferentemente do que ocorrem com as temperaturas máximas, as temperaturas mínimas não apresentam uma distribuição espacial uniforme. Isto é, nos mapas de temperatura máxima a configuração é basicamente, a mesma durante todo o ano, com 

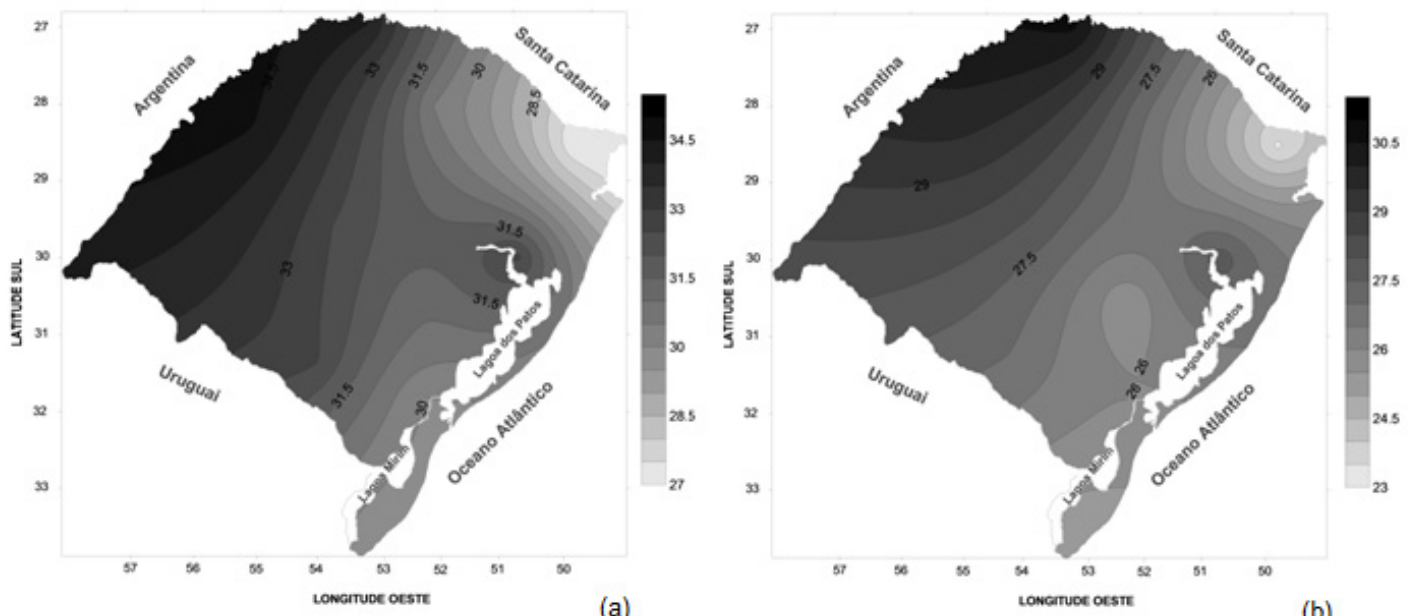

(a)

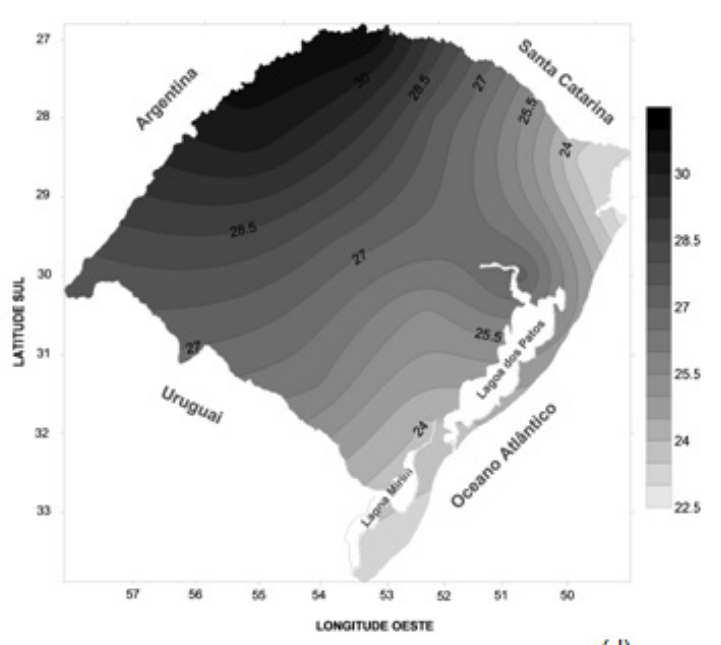

(c)

(d)

Figura 2 - Distribuição espacial dos valores de temperatura máxima de acordo com o limite superior ao $4^{\circ}$ quartil (período 1967- 2005) para os meses de (a) Janeiro, (b) Abril, (c) Julho e (d) Outubro.

o sul e o leste do estado apresentando temperaturas inferiores ao norte e ao oeste; enquanto nos mapas de temperatura mínima, nem sempre as regiões com temperaturas extremas são as mesmas. Por exemplo, nos meses de abril e junho, o leste do Estado apresenta temperaturas bem superiores àquelas do norte e do oeste. De um mês para outro, podemos notar essas diferenças, com exceção de uma zona fria em torno da cidade de Bom Jesus, que se mantém em todos os meses, tanto para temperatura máxima como para a mínima.

A Figura 3a, referente ao mês de janeiro, evidencia uma zona quente a noroeste, compreendendo as estações de São Luiz Gonzaga e Uruguaiana (ZQN), que mesmo menos intensa, afeta o centro (Santa Maria) e o norte (Iraí) do Estado. Outra região onde, notavelmente, a temperatura mínima apresenta valores altos é aquela que compreende a estação de Porto Alegre e litoral norte (ZQL). Observa-se uma zona fria em torno da estação de Bom Jesus (ZFB) que se estende, de forma mais amena, em direção ao centro do estado, afetando Passo Fundo e Bento Gonçalves. Observam-se, também, temperaturas mínimas mais baixas na região Sul do Estado, nas regiões de Santa Vitória, Bagé e Encruzilhada do Sul. Em abril (Figura 3b), nota-se o enfraquecimento da ZFN e o surgimento de uma zona com temperaturas mais baixas em torno de Bagé. Em julho (Figura 3c), as temperaturas voltam a subir na região nordeste, em especial em torno de são Luiz Gonzaga, e Bagé deixa de apresentar temperatura mais baixa, com relação ao restante do Estado. Na Figura 3d observamos que no mês de outubro, as zonas de temperatura mais elevada (ZQN e ZQL) voltam a fortalecer. Nota-se que, em todos os meses, há um núcleo sempre com temperaturas mínimas mais baixas em torno da cidade de Bom Jesus. Em seguida, temperaturas não tão baixas na região de Bagé (Campanha Gaúcha). Há também uma zona permanente com temperaturas mínimas mais altas em Porto Alegre, que se estende até o Litoral Norte do Estado, 

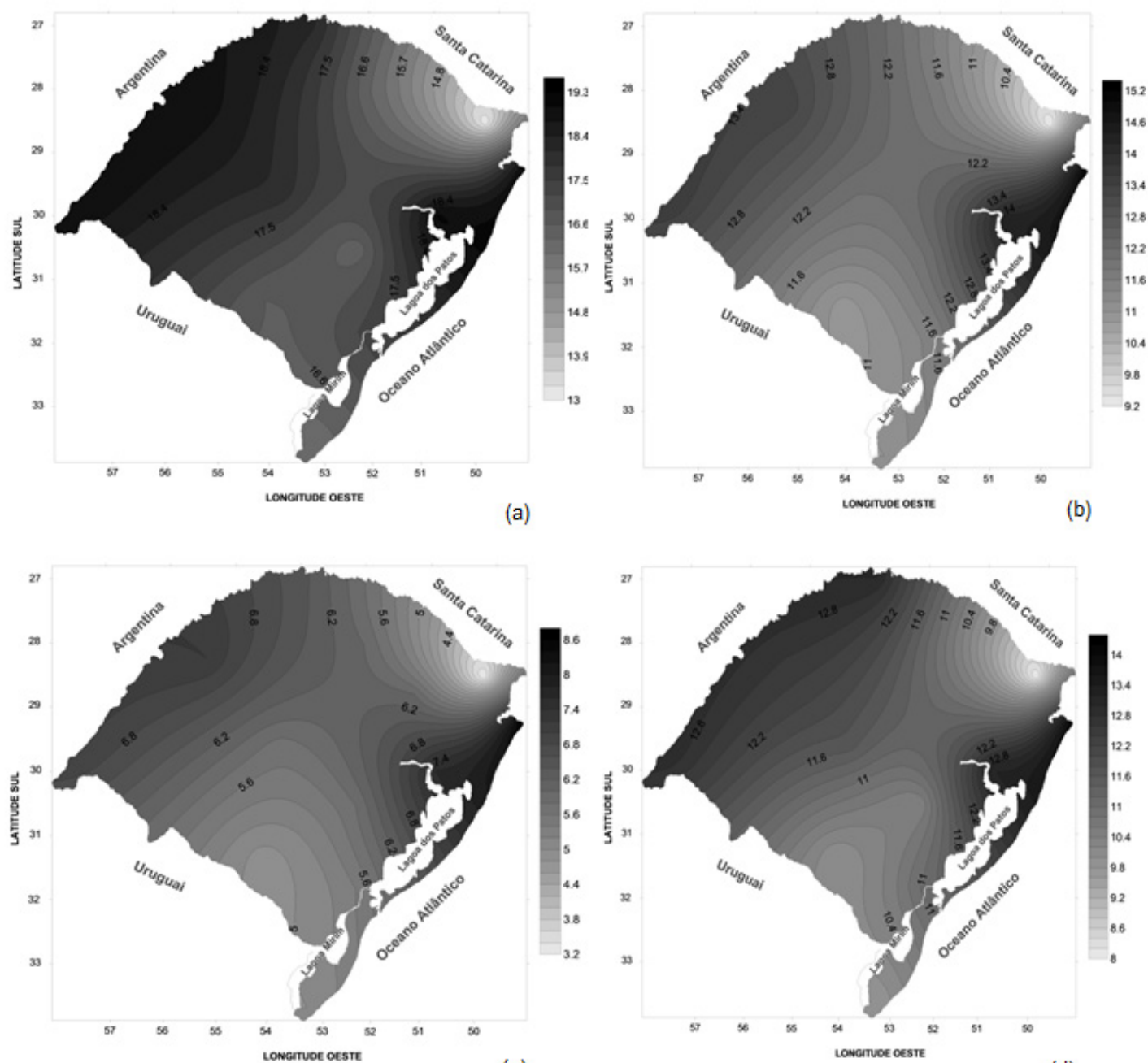

(c)

(d)

Figura 3 - Distribuição espacial dos valores de temperatura mínima de acordo com o limite inferior ao $1^{\circ}$ quartil (período 1967- 2005) para os meses de (a) Janeiro, (b) Abril, (c) Julho e (d) Outubro.

e uma zona com temperaturas altas na região nordeste. Porém, a região quente tem certa variabilidade mensal, apresentando, muitas vezes, temperaturas baixas, se comparadas com o litoral.

Os mapas de temperaturas extremas (Figuras 2 e 3 ) apresentam padrões espaciais muito semelhantes, em todos os meses analisados, tanto para os casos de temperatura máxima, como de temperatura mínima. Por exemplo, o núcleo de temperatura mais baixa localiza-se, sempre, na região em torno da estação de Bom Jesus. Isso se deve ao fato de esta estação estar localizada na região de maior altitude do Estado, como mostrado na Figura 1. Já o núcleo mais quente fica a noroeste, próximo a estação de Uruguaiana. Esta é uma região mais continental e por isso é, em geral, mais quente e seca. Além disso, não é a região preferencial da rota de frentes frias que incursionam no Estado. Assim, além de haver menos chances de ocorrência de eventos que causem quedas bruscas de temperatura, as condições para manutenção do frio são menos favoráveis. Quanto aos mapas apenas de temperatura máxima, o sul do Estado apresenta temperaturas mais baixas do que o sudoeste, o oposto do que mostram os mapas de temperatura mínima, sugerindo que o sudoeste tem maior amplitude térmica. Isso ocorre porque, apesar do sudoeste do RS ser a rota principal das frentes frias, ocasionando queda na temperatura logo após a incursão da zona de alta pressão que sucede a frente, é uma região mais continental (seca), o que facilita a elevação das temperaturas. Já a região mais ao sul do Estado é litorânea, por isso, naturalmente, trata-se de uma zona mais úmida e termicamente mais estável.

\subsection{Comportamento geral das ondas de frio e calor}

\subsubsection{Ondas de frio por mês e por localidade}

Na figura 4, observa-se o comportamento médio mensal das ondas de frio no estado do Rio Grande do Sul. Nota-se um 

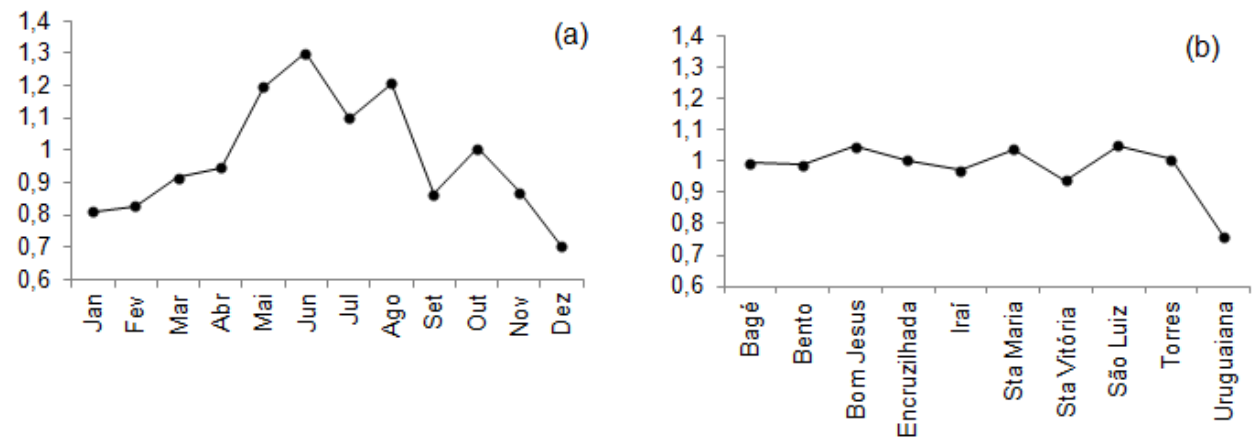

Figura 4 - Freqüência mensal de ondas de frio no Rio Grande do Sul (a) e freqüência anual de ondas de frio nas diferentes estações do Rio Grande do Sul (1967-2005) (b).

comportamento senoidal da curva que representa o número de ondas de frio médio por mês, assim como, ocorre no ciclo anual da temperatura nesta Região. Isto é, ocorrem mais ondas de frio nos meses quando a temperatura mínima é mais baixa no hemisfério austral (maio, junho, julho, agosto), e menos nos meses de temperatura mais elevada (dezembro, janeiro e fevereiro). Isso reforça as observações feitas por Gonçalves (2000), nas quais há uma maior variabilidade das temperaturas mínimas diárias no inverno.

A partir da Figura 4b, onde é exposto o comportamento médio das ondas de frio no estado do Rio Grande do Sul por localidade, nota-se uma homogeneidade dos valores para a maioria destas. A única estação onde esse valor é destoante (não fica entre 0,9 e 1,1) é Uruguaiana. Esta estação (como observado no item 3.1) localiza-se em uma região, em geral, mais quente e seca do estado, havendo menos chances de ocorrência e manutenção de eventos caracterizados por quedas de temperatura.

\subsubsection{Ondas de calor por mês e por localidade}

Pela Figura 5a, que mostra o comportamento médio mensal das ondas de calor no estado do Rio Grande do Sul, nota-se o comportamento heterogêneo dessas ondas. Assim como para as ondas de frio, o maior número de ondas de calor também ocorre no período mais frio do ano, quando a atmosfera está mais instável e sujeita a mudanças de temperatura. O mês de julho é aquele com o maior número médio de ondas de calor, e é nesse mês que, de acordo com a figura 4, nota-se a diminuição de ondas de frio. Segundo Nímer (1989), julho é o mês mais frio do ano, por suceder junho (mês de ocorrência do solstício de inverno), o que representa menos horas diárias de radiação solar, além de haver, nesta época do ano, maior ocorrência de incursões de massas de ar de origem circumpolar.

A Figura $5 \mathrm{~b}$ mostra o comportamento médio das ondas de calor no estado do Rio Grande do Sul por localidade. As estações que apresentam mais ondas de calor são Bom Jesus, Iraí e São Luiz Gonzaga. Apesar das diferenças quanto ao comportamento das temperaturas máximas nessas regiões (item 2.1), pode-se observar pela Figura 1, que estas são as estações presentes neste estudo que se encontram mais ao norte do Estado, região mais sujeita à influência das massas de ar quente provenientes do Norte do país. Já as estações meteorológicas com menor incidência de ondas de calor são Santa Vitória do Palmar e Torres. Elas estão localizadas na parte litorânea do Estado, onde há, devido à maritimidade, menores mudança de temperatura.
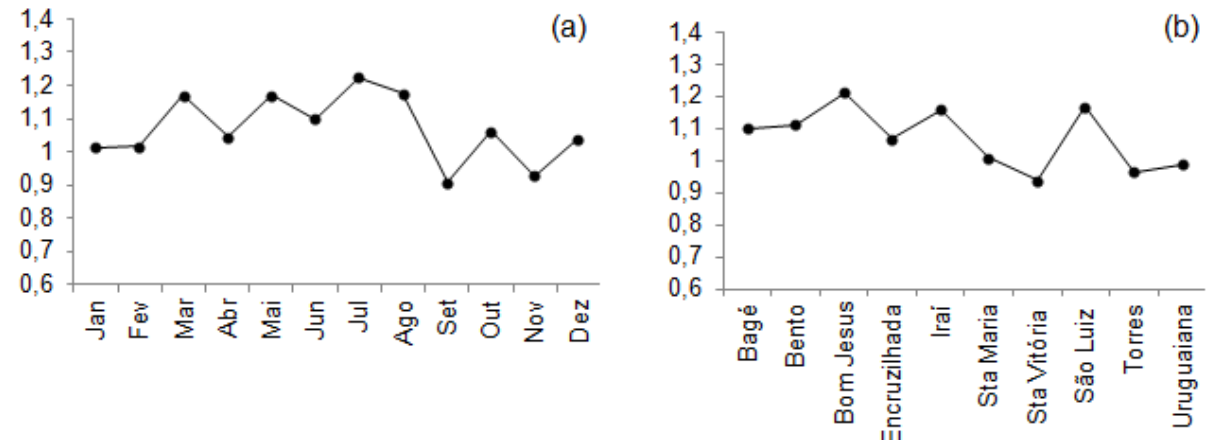

Figura 5 - Freqüência mensal de ondas de calor no Rio Grande do Sul (a) e freqüência anual de ondas de calor nas diferentes estações do Rio Grande do Sul (1967-2005) (b). 


\subsection{Casos particulares}

Através do cálculo das anomalias, descritos anteriormente neste trabalho, obteve-se tabelas que mostram os menores e os maiores períodos de anomalias de temperatura (ondas), para determinados meses de interesse para cada uma das estações estudadas.

A Tabela 3 mostra o menor período considerado (5 dias) de anomalias negativas de temperatura mínima (onda de frio): na primeira coluna encontram-se as estações; na segunda, o mês com o maior número de ocorrências de anomalias de 5 dias, durante o período estudado. Na terceira coluna está o maior valor de anomalia encontrado dentre estes períodos selecionados, seguida pela quarta coluna, que expressa o ano de ocorrência dessa anomalia. Observa-se que mais ondas de frio (de 5 dias) ocorrem, para a maioria das estações, nos períodos mais frios do ano (meses de junho, julho e agosto). Apenas a estação de Uruguaiana apresentou mais ondas em um período diferente, no mês de outubro.

Na Tabela 4, têm-se os maiores períodos de ondas de frio, nos 39 anos de estudo (1967 - 2005), para cada uma das estações meteorológicas escolhidas, o maior número de dias consecutivos de anomalia negativa de temperatura mínima, o(s) mês(es) onde esta onda foi encontrada, o maior valor de anomalia e o ano correspondente a esta onda.

Ao contrário do que se observa quanto ao maior número de ondas de 5 dias, as ondas de frio mais extensas ocorrem, na maioria das estações, nos meses mais quentes (entre dezembro e abril). A exceção é Encruzilhada do Sul (em julho de 2000), além de São Luiz Gonzaga que, assim como em abril e dezembro, também apresenta uma onda de frio de 22 dias em julho de 2000. É valido salientar que no ano de 2000, segundo Pezza e Ambrizzi (2005), ocorreram temperaturas mínimas recordes no inverno. Isso, provavelmente, devido ao fato desse ser um ano de La Niña, que foi registrada como a mais duradora durante o período estudado, tendo a duração de 24 meses (Julho 1998 - Junho 2000), como mostra a Tabela 1. Maio de 1978 ainda aparece como um mês de grandes ondas de frio para Santa Maria e Uruguaiana. Ao simular os campos mensais de anomalia de pressão e geopotencial em $500 \mathrm{mb}$, utilizando os dados de reanálise do NCEP/NCAR, disponíveis no sítio http://www.esrl.noaa.gov/psd/cgi-bin/ data/composites/printpage.pl, nota-se que nesse período há a permanência de um bloqueio seguindo o padrão dipolo, o que barraria a incursão de transientes na região (Nascimento e Ambrizzi, 2002), contribuindo para a não ocorrência de chuvas e a manutenção da temperatura, neste caso, baixa temperatura.

A Tabela 5 mostra o menor período ( 5 dias) de anomalias positivas de temperatura máxima (onda de calor) e, na Tabela 6 , tem-se os maiores períodos de ondas de calor, todas em 39 anos estudados.

Na Tabela 5, nota-se como é variável a distribuição do maior número de ondas de calor de pouca duração ( 5 dias) no Estado, quanto ao mês em que ocorrem. Apenas 2 das 10 estações (Bagé, Bento Gonçalves) têm mais ondas nos meses mais quentes (dezembro, janeiro). Bom Jesus, ainda, apresenta esse maior valor em abril, um mês de temperaturas entre altas e amenas. Somente Encruzilhada do Sul e Torres apresentam mais ondas no período mais frio (julho e agosto). Já 5 estações (Iraí, Santa Maria, Santa Vitória do Palmar, São Luiz Gonzaga e Uruguaiana) apresentam mais ondas de calor de 5 dias no mesmo mês, outubro. A partir da Tabela 6 , nota-se que os meses de fevereiro, março, maio e agosto são aqueles em que ocorrem mais ondas de calor extensas, dependendo da estação.

Tabela 3 - Meses com mais ondas de frio (5 dias), maiores valores de anomalia numa única onda, e ano de ocorrência e intervalo de anomalia, para cada localidade, no período de 1967-2005.

\begin{tabular}{lccc}
\hline \multicolumn{1}{c}{ Localidades } & $\begin{array}{c}\text { Mês } \\
\left(\mathrm{N}^{\circ} \text { de }\right. \\
\text { ocorrências/total })\end{array}$ & $\begin{array}{c}\text { Maior Anomalia } \\
\left({ }^{\circ} \mathrm{C}\right)\end{array}$ & $\begin{array}{c}\text { Ano de } \\
\text { Ocorrência }\end{array}$ \\
\hline Bagé & Julho $(21 / 49)$ & $-11,16$ & 1975 \\
Bento Gonçalves & Junho $(15 / 46)$ & $-11,40$ & $08 / 1970$ \\
& Agosto $(15 / 46)$ & & \\
Bom Jesus & Agosto $(22 / 61)$ & $-12,42$ & 1992 \\
Encruzilhada do Sul & Junho $(18 / 48)$ & $-9,79$ & 1984 \\
Iraí & Agosto $(16 / 56)$ & $-10,38$ & 1972 \\
Santa Maria & Agosto $(17 / 61)$ & $-14,65$ & 1999 \\
Santa Vitória do Palmar & Junho $(19 / 50)$ & $-7,96$ & 1989 \\
São Luiz Gonzaga & Junho $(19 / 41)$ & $-12,04$ & 1979 \\
Torres & Junho $(16 / 40)$ & $-9,35$ & 1988 \\
Uruguaiana & Outubro $(14 / 52)$ & $-10,9$ & 1974 \\
\hline
\end{tabular}


Tabela 4 - Maiores ondas de frio ocorridas em cada localidade no período de 1967-2005, mês de ocorrência, maior valor da anomalia (em caso de mais de uma onda com mesma extensão), e ano de ocorrência.

\begin{tabular}{|c|c|c|c|c|}
\hline Localidades & $\mathrm{N}^{\mathrm{o}}$ de dias & $\begin{array}{l}\text { Mês }\left(\mathrm{N}^{\circ} \mathrm{de}\right. \\
\text { anomalias } \\
\text { observadas) }\end{array}$ & $\begin{array}{c}\text { Maior } \\
\text { Anomalia } \\
\left({ }^{\circ} \mathrm{C}\right)\end{array}$ & Ano \\
\hline Bagé & 24 & Dezembro (1) & $-7,66$ & 1984 \\
\hline Bento Gonçalves & 30 & $\operatorname{Março~(1)~}$ & $-10,76$ & 1976 \\
\hline Bom Jesus & 23 & Janeiro (1) & $-7,9$ & 1975 \\
\hline Encruzilhada do Sul & 21 & Julho (1) & $-10,25$ & 2000 \\
\hline Iraí & 30 & Janeiro (1) & $-5,37$ & 1967 \\
\hline Santa Maria & 27 & Maio (1) & $-15,35$ & 1978 \\
\hline Santa Vitória do Palmar & 24 & Dezembro (1) & $-9,07$ & 1984 \\
\hline São Luiz Gonzaga & 22 & $\begin{array}{l}\text { Abril (1) } \\
\text { Julho (1) }\end{array}$ & $-11,41$ & $07 / 2000$ \\
\hline Torres & 28 & $\begin{array}{c}\text { Dezembro (1) } \\
\text { Janeiro (1) } \\
\text { Fevereiro (1) }\end{array}$ & $-5,87$ & $01 / 1979$ \\
\hline Uruguaiana & 24 & $\begin{array}{c}\text { Fevereiro (1) } \\
\text { Maio (1) }\end{array}$ & $-14,85$ & $05 / 1978$ \\
\hline
\end{tabular}

Tabela 5 - Meses com mais ondas de calor (5 dias), maiores valores de anomalia numa única onda e ano de ocorrência, para cada localidade, no período de 1967-2005

\begin{tabular}{lccc}
\hline \multicolumn{1}{c}{ Localidades } & $\begin{array}{c}\text { Mês }\left(\mathrm{N}^{\circ} \text { de anomalias }\right. \\
\text { encontradas/total) }\end{array}$ & $\begin{array}{c}\text { Maior Anomalia } \\
\left({ }^{\circ} \mathrm{C}\right)\end{array}$ & Ano \\
\hline Bagé & Dezembro $(16 / 49)$ & 7,06 & 1996 \\
Bento Gonçalves & Janeiro $(17 / 42)$ & 8,88 & 1986 \\
Bom Jesus & Abril $(19 / 49)$ & 6,91 & 1994 \\
Encruzilhada do Sul & Julho $(19 / 56)$ & 9,76 & 1977 \\
Iraí & Outubro $(17 / 40)$ & 8,49 & 1991 \\
Santa Maria & Outubro $(25 / 43)$ & 12,18 & 1985 \\
Santa Vitória do Palmar & Outubro $(17 / 38)$ & 9,11 & 1969 \\
São Luiz Gonzaga & Outubro $(23 / 43)$ & 9,69 & 1985 \\
Torres & Agosto $(13 / 38)$ & 10,72 & 1986 \\
Uruguaiana & Outubro $(14 / 31)$ & 10,12 & 1977 \\
\hline
\end{tabular}

\subsection{Relações ENOS x Ondas}

A partir de comparações feitas por análise de compostos, notou-se que, para a maioria dos meses, ocorrem mais ondas de frio na presença de La Niñas e menos nos casos de El Niños. Da mesma forma, ocorrem mais ondas de calor durante eventos de El Niño. Isso era esperado, baseado em resultados de trabalhos anteriores relacionando ENOS com temperaturas no Rio Grande do Sul e regiões próximas (Rusticucci e Vargas, 2001; Grimm e Togatliam, 2002). Por isso, as tabelas de contingência, avaliadas pelo teste de Fisher, foram arranjadas de forma a comparar as relações apenas entre Ondas de Calor e El Niño e, após, entre Ondas de Frio e La Niña. Também foram selecionadas para as análises, apenas os meses centrais de cada estação do ano: janeiro (verão), abril (outono), julho (inverno) e outubro (primavera), por serem considerados representativos.

\subsubsection{EI Niño x Ondas de calor}

Um comparativo entre os quatro meses de estudo, com os resultados dos testes de hipótese baseados na distribuição hipergeométrica para as relações entre a ocorrência de ondas de calor e os eventos El Niño, encontram-se na Figura 6a. Nota-se, para a maioria das localidades, que o mês em que as relações são mais significativas é o mês de julho, que corresponde ao inverno austral, justamente o mês que se destaca com relação aos demais pelo maior número de ocorrência de ondas de calor. As únicas estações onde isso não foi observado, foram as estações correspondentes a regiões litorâneas (Santa Vitória e Torres), estações estas que, como visto na secção 3.2 deste trabalho, também são aquelas com menor ocorrências de ondas de calor, quando comparadas com as demais. 
Tabela 6 - Maiores ondas de calor ocorridas em cada localidade no período de 1967-2005, mês de ocorrência, maior valor da anomalia (em caso de mais de uma onda com mesma extensão), e ano de ocorrência.

\begin{tabular}{lcccc}
\hline \multicolumn{1}{c}{ Localidades } & Nês (No de & $\begin{array}{c}\text { Maior } \\
\text { anomalias } \\
\text { encontradas) }\end{array}$ & $\begin{array}{c}\text { Anomalia } \\
\left({ }^{\circ} \mathrm{C}\right)\end{array}$ & Ano \\
\hline Bagé & 20 & Fevereiro (1) & 8,32 & 1989 \\
Bento Gonçalves & 30 & Maio (1) & 9,66 & 1967 \\
Bom Jesus & 21 & Fevereiro (1) & 4,42 & 1977 \\
Encruzilhada do Sul & 19 & Março (1) & 9,56 & 1988 \\
Iraí & 23 & Maio (1) & 6 & 1996 \\
Santa Maria & 20 & Fevereiro (1) & 6,08 & 1984 \\
Santa Vitória do Palmar & 22 & Agosto (1) & 7,69 & 1989 \\
São Luiz Gonzaga & 26 & Março (1) & 9,06 & 1988 \\
Torres & 23 & Março (1) & 6,83 & $05 / 1981$ \\
& & Maio (1) & & \\
Uruguaiana & 21 & Maio (1) & 9,4 & 1980 \\
\hline
\end{tabular}

As estações de Bom Jesus, Encruzilhada do Sul, Iraí, Santa Maria, São Luiz Gonzaga e Uruguaiana apresentaram nível de confiança acima de $90 \%$ para o mês de julho. Bom Jesus, a estação com maior número de ondas de calor (secção 3.2) obteve nível de confiança acima de $90 \%$ também nos meses de abril e outubro, isto é, nesta estação a persistência das relações entre o número de ondas de calor e El Niño foi maior. Apenas Bagé e Iraí apresentaram nível de significância de até 10\% para o mês de janeiro, mês onde ocorre a fase madura do fenômeno ENOS, o que mostra que há defasagem entre a ocorrência dos eventos El Niño e o seu impacto no surgimento de ondas de calor no Rio Grande do Sul.

\subsubsection{La Niña x Ondas de frio}

Quanto às relações entre os eventos La Niña e as Ondas de Frio no Rio Grande do Sul, notam-se resultados diferentes.
Na Figura 6 b observa-se que o mês de destaque, quanto ao valor do nível de confiança das relações, é abril. Outubro também aparece em destaque para algumas estações. Esses resultados ainda sugerem a defasagem entre a ocorrência de La Niña e seu impacto nas Ondas de Frio, como foi visto para Ondas de calor e El Niño, uma vez que janeiro aparece como um mês onde as relações são fracas, na maioria das estações. Porém, desta vez, verifica-se que esse impacto é menos evidente no mês de julho, referente ao inverno, o contrário do que foi observado para as Ondas de Calor.

\section{CONCLUSÕES}

A variabilidade sazonal das ondas de frio é diferente da observada para as ondas de calor no estado do Rio Grande do Sul. A ocorrência de ondas de frio apresenta um comportamento senoidal, assim como, observado no ciclo anual da temperatura,
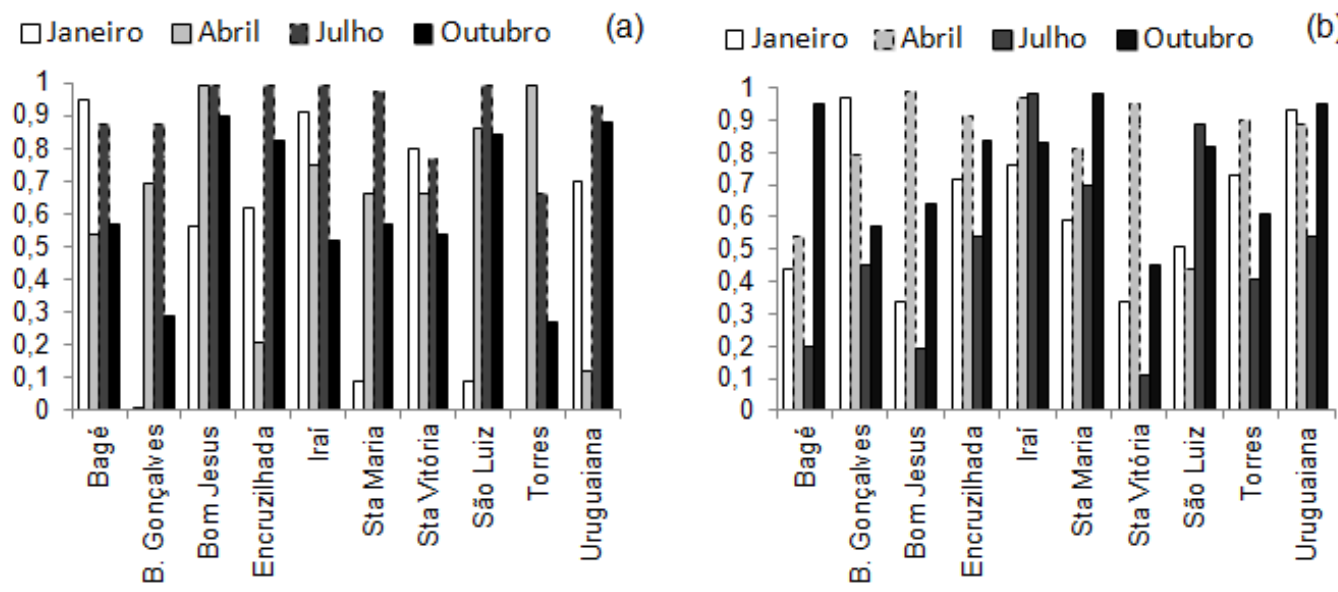

Figura 6 - Nível de confiança das relações entre Ondas de Calor e ocorrência de El Niño (a) e entre Ondas de Frio e ocorrência de La Niña (b) para os quatro meses de estudo nas 10 localidades do RS. 
ocorrendo mais ondas de frio nos meses com as temperaturas mínimas mais baixas. Para as ondas de calor, por outro lado, nota-se um comportamento heterogêneo, o maior número de ondas de calor também ocorre no período mais frio do ano, quando a atmosfera está mais instável e sujeita a mudanças de temperatura. $\mathrm{O}$ mês de julho é aquele com o maior número de ondas de calor, e é nesse mês que se nota a diminuição de ondas de frio.

Existe homogeneidade no número de ocorrências de ondas de frio para a maioria das localidades. Aúnica estação onde esse valor é destoante com relação às demais é Uruguaiana, que se localiza na região mais quente do estado. Já as estações que apresentam mais ondas de calor são aquelas localizadas ao norte do Estado, região sujeita à influência das massas de ar quente, provenientes do Norte do país. As estações meteorológicas com menor incidência de ondas de calor são as litorâneas, onde há, devido à maritimidade, menores mudanças de temperatura.

$\mathrm{Na}$ análise de casos extremos, observou-se que mais ondas de frio (de 5 dias) ocorrem nos períodos mais frios do ano (junho, julho e agosto). Apenas a estação de Uruguaiana apresentou mais ondas em um período diferente, no mês de outubro. Quanto à persistência, as ondas de frio mais extensas ocorrem, na maioria das localidades, nos meses mais quentes (entre dezembro e abril).

A distribuição do maior número de ondas de calor de pouca duração (5 dias) é variável no Estado, em relação ao mês em que ocorrem. Apenas 2 das 10 localidades têm mais ondas nos meses mais quentes (dezembro e janeiro). Fevereiro, março, maio e agosto são os meses em que ocorrem mais ondas de calor extensas, dependendo da estação.

Em relação à variabilidade interanual associada ao ENOS, da análise de compostos, notou-se que, para a maioria dos meses, ocorrem mais ondas de frio nos casos de La Niña e menos nos de El Niño; e, da mesma forma, mais ondas de calor ocorrem em anos de El Niño. O teste de Fisher, para as relações entre a ocorrência de ondas de frio e La Niña e ondas de calor e El Niño, revelou que, na maioria das localidades, o mês de julho é aquele em que as relações entre a ocorrência de ondas de calor e os eventos El Niño são mais significativas, mês que se destaca com relação aos demais pelo maior número de ocorrência de ondas de calor e que corresponde ao inverno. As únicas localidades onde isso não foi observado foram aquelas correspondentes a regiões litorâneas, localidades estas que também têm menores ocorrências de ondas de calor, quando comparadas com as demais. A maior parte das localidades apresentou nível de confiança acima de $90 \%$ para o mês de julho. Em Bom Jesus, localidade com maior número de ondas de calor, a persistência das relações entre o número de ondas de calor e El Niño foi maior. Quanto às relações entre os eventos La Niña e as Ondas de Frio, os resultados foram diferentes. O mês, no qual o nível de confiança das relações foi mais alto, para a maioria das estações, foi abril. Outubro também aparece em destaque para algumas estações. Em ambos os casos, nota-se que há defasagem entre a ocorrência dos eventos El Niño/La Niña e o seu impacto no surgimento de ondas de calor/frio no Rio Grande do Sul. Janeiro, mês onde os fenômenos estariam em sua fase madura, aparece como um mês onde as relações são fracas para a maioria das estações. A diferença está que para La Niña, o impacto nas ondas de frio é maior em abril e menos evidente em julho, mês referente ao inverno, o contrário do que ocorre quanto à relação El Niño X ondas de calor.

\section{AGRADECIMENTOS}

À CAPES, pela concessão de bolsa de mestrado, período em que parte do trabalho foi realizado, e ao CNPq, pela concessão da bolsa de doutorado ao primeiro autor.

\section{REFERÊNCIAS BIBLIOGRÁFICAS}

AGRESTI, A. Introduction to Categorical Data Analysis. New Jersey: John Wiley, 1996. 290p.

ARKIN, P. A. The relationship between interannual variability in the $200 \mathrm{mb}$ tropical wind field and Southern Oscillation.

Monthly Weather Review, v. 110, n. 10, p. 1393-1404, 1982.

BIDEGAIN, M. E RENON, M. Temperaturas extremas y amplitudes diárias en Uruguay condicionadas según el fenomeno ENOS. In: CONGRESSO BRASILEIRO DE METEOROLOGIA, 12, 2002, Foz do Iguaçu. Anais... Foz do Iguaçu: SBMET, 2002 CD-ROM.

BJERKNES, J. A. A possible response of the atmospheric Hadley circulation to equatorial anomalies of ocean temperature. Tellus, v.18, n.4, p.820-829, 1966.

CAVALCANTI, I. F. A. ; KOUSKY, V. E. Climatology of South American cold fronts. In: International Conference on Southern Hemisphere Meteorology and Oceanography, 7, 2003, Wellington. Anais... Welington, New Zealand: American Meterological Society, 2003 CD-ROM.

CAVALCANTI, I. F. A. ; KOUSKY, V. E. Frentes Frias sobre o Brasil. In: CAVALCANTI, I. F. A.; FERREIRA, J.F.; JUSTI DA SILVA, M.G.A; SILVA DIAS, M.A.F. Tempo e Clima no Brasil. São Paulo: Oficina de Texto, 2009. Cap.9, p. 135-147.

GONÇALVES, A. M. Estudo da variabilidade climática no estado do Rio Grande do Sul, através das repetições de anomalias de temperaturas mínimas diárias. In: CONGRESSO BRASILEIRO DE METEOROLOGIA, 11, 2000, Rio de Janeiro. Anais do... Rio de Janeiro: SBMET, 2000 CD-ROM. 
GRIMM, A.M.; TOGATLIAN, I.M. Relação entre eventos El Niño /La Niña e freqüência de extremos frios e quentes de temperatura no Cone Sul da América do Sul. In: CONGRESSO BRASILEIRO DE METEOROLOGIA, 12, 2002, Foz do Iguaçu. Anais do... Foz do Iguaçu: SBMET, 2002. CD-ROM.

GRIMM, A. M. The El Niño impact on the summer monsoon in Brazil: regional processes versus remote influences. Journal of Climate, v. 16, n. 1, p. 263-280, 2003.

KAYANO, M. T.; ANDREOLI, R. V. Relations of South American summer rainfall interannual variations with the Pacific Decadal Oscillation. International Journal of Climatology, v. 27, p. 531-540, 2007.

KENDALL, M.; STUART, A. The Advanced Theory of Statistics, Vol. 2. New York: Macmillan. 1979.

KILADIS, G.N.; DIAZ, H.F. Global climate anomalies associated with extremes in the Southern Oscillation. Journal of Climate, v.2, p. 1069-1090, 1989.

KILADIS, G.N.; K.MO, Interannual and intraseasonal variability in the Southern Hemisphere. In: KAROLY, D.; VINCENT, D. (ed) Meteorological Monographs. American Meteorological Society, v. 27, n. 49, p. 307- 333, 1998.

NASCIMENTO, E.L.; AMBRIZZI, T. The influence of atmospheric blocking on the Rossby wave propagation in Southern Hemisphere flows. J. Meteorol. Soc. Japan, v.80, p.139-159, 2002.

NÍMER, E. Climatologia do Brasil. Rio de Janeiro: IBGE Departamento de Recursos Naturais e Estudos Ambientais. 2. Ed, 1989, 421p.

PEZZA, A.B.; AMBRIZZI, T. Cold waves in South América and freezing temperatures in São Paulo: Historical background (1888-2003) and cases studies of cyclone and anticyclone tracks. Revista Brasileira de Meteorologia, v.20, n.1, p. 141-158, 2005.
RAO, V.B.; HADA, K. Characteristics of Rainfall over Brazil: Annual Variations and Connections with the Southern Oscillations. Theoretical and Applied Climatology, v. 42, p. 81-91, 1990.

ROPELEWSKI, C.F.; M.S. HALPERT Global and regional scale precipitation patterns associated with the El Niño Southern Oscillation. Monthly Weather Review, v. 115, p. 1606-1626, 1987.

RUSTICUCCI, M.M.; VARGAS, W.M. Interannual variability of temperature spells over Argentina. Atmósfera, v.14, p. 75-86, 2001.

SANSIGOLO, C.A.; DINIZ, G.B. E MACHADO J.P. Impacto das fases extremas do ENOS nas temperaturas médias sazonais do Rio Grande do Sul. In: Congresso Brasileiro de Meteorologia, 14, 2006, Florianópolis. Anais... Florianópolis: SBMET, 2006 CD-ROM.

STUDZINSKI, C.D.; DIAZ, A.F. Relação da precipitação no sul do Brasil-Uruguai com a temperatura da superfície do mar (TSM) por correlações canônicas (CCA). In: PESSOA, M.L.; MINE, M.R.M.; LEITE, E.A. (Coord.). Meteorologia e hidrologia: Aspectos e considerações no contexto brasileiro. Curitiba: Sistema Meteorológico do Paraná (Simepar), p.191-205, 1994.

TRENBERTH, K. E. The definition of El Niño. Bulletin of the American Meteorological Society, v. 78, n. 12, p. 27712777, 1997.

WANG, C. Atmospheric circulation cells associated with the El-Niño/Southern Oscillation. Journal of Climate, v.15, n.4, p.399-419, 2002. 